\title{
Anti-Aging and Tissue Regeneration Ability of Policosanol Along with Lipid-Lowering Effect in Hyperlipidemic Zebrafish via Enhancement of High-Density Lipoprotein Functionality
}

\author{
Eun-Young Lee, ${ }^{1-3,{ }^{*}}$ Jeong-Ah Yoo, ${ }^{1-3,{ }^{*}}$ So-Mang Lim, ${ }^{1-3}$ and Kyung-Hyun Cho ${ }^{1-3}$
}

\begin{abstract}
We investigated the tissue regeneration and lipid-lowering effects of policosanol (PCO) by employing a hyperlipidemic zebrafish model. A reconstituted high-density lipoprotein containing policosanol (PCO-rHDL) facilitated greater cell growth and replication with less apoptosis and reactive oxygen species (ROS) production in BV-2 microglial cell lines. From in vivo study, injection of rHDL containing apolipoprotein A-I (ApoA-I) caused $76 \pm 4 \%$ $(p=0.01)$ greater tissue regeneration activity than the phosphate-buffered saline (PBS) control, whereas PCOrHDL caused $94 \pm 7 \%(p=0.002)$ increased regeneration. PCO in ethanol $(\mathrm{EtOH})$ showed lower cholesteryl ester transfer protein (CETP) inhibitory ability than did anacetrapib, whereas PCO-rHDL showed higher inhibitory ability than anacetrapib, suggesting a synergistic effect between PCO and rHDL. Following 9 weeks of PCO consumption, the PCO group ( $0.003 \%$ PCO in Tetrabit) showed the highest survivability ( $80 \%)$, whereas normal diet (ND) and high-cholesterol diet (HCD) control groups showed $67 \%$ and $70 \%$ survival rates, respectively. Supplementation with a HCD resulted in two-fold elevation of CETP activity along with 3 - and 2.5-fold increases in serum total cholesterol (TC) and triglycerides (TGs) levels, respectively. Consumption of PCO for 9 weeks resulted in $40 \pm 5 \%$ ( $p=0.01$ vs. HCD) and $33 \pm 4 \%$ ( $p=0.02$ vs. HCD) reduction of TC and TGs levels, respectively. Serum high-density lipoprotein cholesterol (HDL-C) level increased up to $37 \pm 2 \mathrm{mg} / \mathrm{dL}(p=0.004)$, whereas the percentage of HDL-C/TC increased up to $20 \pm 2 \%$ from $5 \pm 1 \%$ compared to the HCD control. The serum glucose level was reduced to $47 \pm 2 \%$ ( $p=0.002)$ compared to the HCD control. Fatty liver change and hepatic inflammation levels were remarkably increased upon HCD consumption and were two-fold higher than that under ND. However, the PCO group showed 58 $\pm 5 \%(p=0.001)$ and 50 $\pm 3 \%(p=0.006)$ reduction of inflammation enzyme levels and lipid content in hepatic tissue under HCD. In conclusion, PCO supplementation showed lipid-lowering and HDL-Celevating effects with ameliorating fatty liver change. These in vivo anti-atherosclerotic and anti-diabetic effects of PCO are well associated with in vitro anti-apoptotic activities.
\end{abstract}

\section{Introduction}

$\mathbf{P}$ OLICOSANOL (PCO) IS AN EFFECTIVE food ingredient and dietary supplement for lowering serum low-density lipoprotein cholesterol (LDL-C), total cholesterol (TC), and triglycerides (TGs) concentrations in humans and animal models. ${ }^{1}$ The lipid-lowering effect of PCO has been dem- onstrated in several animal models. ${ }^{2-4}$ In anti-atherosclerotic activity, PCO administration has been shown to reduce formation of foam cells as well as atherosclerosis in a rat model. ${ }^{5}$

Although the lipid-lowering effect of PCO has been well established in mouse, rat, rabbit, and dog models, its LDL-C-lowering and high-density lipoprotein cholesterol (HDL-C)-elevating effects have not been elucidated clearly.

\footnotetext{
${ }^{1}$ School of Biotechnology, Yeungnam University, Gyeongsan, Republic of Korea.

${ }^{2}$ Research Institute of Protein Sensor, Yeungnam University, Gyeongsan, Republic of Korea

${ }^{3}$ BK21plus Program Serum Biomedical Research and Education Team, Yeungnam University, Gyeongsan, Republic of Korea.

*These authors are co-first authors.
}

(C) Eun-Young Lee et al., 2016; Published by Mary Ann Liebert, Inc. This Open Access article is distributed under the terms of the Creative Commons Attribution Noncommercial License (http://creativecommons.org/licenses/by-nc/4.0/) which permits any noncommercial use, distribution, and reproduction in any medium, provided the original author(s) and the source are credited. 
Specifically, the lipid-lowering activity of PCO may be due, at least in part, to inhibition of 3-hydroxy-3-methylglutarylcoenzyme A (HMG-CoA) reductase, ${ }^{6}$ which is a target for statin drugs, or increased receptor-mediated uptake of LDL in the liver. ${ }^{7}$ On the other hand, inhibition of cholesterol synthesis by PCO has not been observed directly, which suggests that inhibition occurs before mevalonate formation. In a previous study, we reported that PCO can inhibit cholesteryl ester transfer protein (CETP) activity, which is an atherogenic factor in serum. However, many animal models such as mice, rats, and dogs lack serum cholesteryl ester (CE) transfer activity due to the absence of CETP. ${ }^{8}$ This explains why many reports have not observed any changes in serum CE transfer activity due to PCO, even though HDL-C elevation via CETP inhibition is well known.

Besides lipid metabolism, CETP deficiency is involved in longevity. A mutation of CETP $(I 406 \mathrm{~V})$, resulting in loss of $\mathrm{CE}$ transfer activity, also causes exceptional longevity via elevation of HDL-C with larger-sized HDL particles ${ }^{9}$ and decreased CETP activity. Furthermore, HDL exerts many beneficial effects for maintenance of health, including antioxidant, anti-inflammatory, and anti-thrombotic effects. ${ }^{10} \mathrm{~A}$ higher level of HDL-C is inversely correlated with incidence of Alzheimer's disease. ${ }^{11}$ Because discoidal HDL can penetrate the blood-brain barrier (BBB), ${ }^{12}$ glial cells are influenced by composition of HDL. To overcome any insolubility, we incorporated PCO into reconstituted HDL along with apolipoprotein A-I (ApoA-I) in isotonic buffer for cell treatment. PCOreconstituted high-density lipoprotein (rHDL) was treated to BV-2 cells (microglial cells) to test the potential activity of PCO in enhancing brain cell viability and replication.

To investigate the physiologic effect of PCO in vertebrate animals, we used a zebrafish (Danio rerio) model displaying induction of hypercholesterolemia by a high-cholesterol diet (HCD) to mimic early atherogenesis and its complications, as suggested by our group ${ }^{13}$ and Miller's group. ${ }^{14}$ Adult zebrafish consuming a HCD for several weeks showed induction of atherosclerosis symptoms, including hypercholesterolemia, lipoprotein oxidation, and fatty streak formation. Zebrafish display high serum CETP activity and are thus a more suitable animal model to test CETP inhibition. It has been well established that hypercholesterolemic zebrafish are a useful and highly informative experimental model of atherosclerosis and vascular inflammation.

\section{Materials and Methods}

\section{Materials}

PCO-sugar cane wax alcohol was obtained from Rainbow \& Nature Pty, Ltd. (Sydney, Australia). PCO contains several chains of various length, including 1-tetracosanol (0.120.0), 1-heptacosanol (1.0-30.0), 1-nonacosanol (1.0-20.0), 1-dotriacontanol (50.0-100.0), 1-hexacosanol (30.0-100.0), 1-octacosanol (600.0-700.0), 1-triacontanol (100.0-150.0), and 1-tetratriacontanol (1.0-50.0).

\section{Purification of human lipoprotein}

LDL $(1.019<\mathrm{d}<1.063), \mathrm{HDL}_{2}(1.063<\mathrm{d}<1.125)$, and $\mathrm{HDL}_{3}(1.125<\mathrm{d}<1.225)$ were isolated via sequential ultracentrifugation from sera of young human males (mean age, $22 \pm 2$ years, $n=18$ ) who voluntarily donated blood after fasting overnight. Density was appropriately adjusted by addition of $\mathrm{NaCl}$ and $\mathrm{NaBr}$, and procedures were carried out in accordance with standard protocols. ${ }^{15}$ Samples were centrifuged for $24 \mathrm{hr}$ at $10^{\circ} \mathrm{C}$ at $100,000 \times g$ using a Himac CP-90 $\alpha$ (Hitachi, Tokyo, Japan) at the Instrumental Analysis Center of Yeungnam University. After purification, the content of advanced glycated end products was determined to compare extent of aging in each lipoprotein using fluorospectrometry as described previously. ${ }^{16}$

\section{Synthesis of $r H D L$}

rHDL containing PCO was prepared by the sodium cholate dialysis method at initial molar ratios of 95:5:1:1 and 95:5:1:5 for POPC:cholesterol:ApoA-I:PCO. ${ }^{17}$ The size and hydrodynamic diameter of rHDL particles were determined by $8 \%-25 \%$ native polyacrylamide gradient gel electrophoresis (PAGGE; cat. no. \#17-0542-01, Pharmacia Phast system) based on comparison with standard globular proteins (GE Healthcare, Uppsala, Sweden) using the Pharmacia Phast System (GE Healthcare, Uppsala, Sweden).

\section{Cell culture and apoptosis}

BV-2 microglial cells were cultured in Dulbecco's modified Eagle medium (DMEM) and maintained at $70 \%$ confluency. Cells were treated with either PCO in organic solvent or PCO-rHDL and incubated for $4 \mathrm{hr}$. After incubation, the extent of apoptosis was measured by Acridine Orange (cat. no. A9231, Sigma) staining and detected by fluorescence detection $(E x=502 \mathrm{~nm}, \mathrm{Em}=525 \mathrm{~nm})$. Production of reactive oxygen species (ROS) by cells was observed by dihydroethidium (DHE) staining $(\mathrm{Ex}=588 \mathrm{~nm}, \mathrm{Ex}=605 \mathrm{~nm})$.

\section{Tissue regeneration}

Enhancement of the tissue regeneration effect of $\mathrm{PCO}$ was tested using a streptozotocin (STZ)-induced adult zebrafish diabetes model, according to our previous report. ${ }^{18} \mathrm{Ap}$ proximately 12 -week-old experimental zebrafish were anesthetized by submersion in 2-phenoxyethanol (cat. no. P1126, Sigma, St. Louis, MO) in system water (1:1000 dilution). Subcutaneous STZ injection at the nearby urostyle was carried out with a 25-gauge needle and micro-syringe (SGE, Ringwood, Australia). Control zebrafish were injected with the same volume of buffer. For fin regeneration studies, STZ-induced zebrafish were anesthetized and tail fins cut with a scalpel close to the proximal branch point of the dermal rays within the fin. After amputation, $10 \mu \mathrm{L}$ of PCO-rHDL (7.5 $\mu \mathrm{g}$ of ApoA-I) was injected into the tail muscle near the urostyle ( $n=9$ for each group). Following injection, fish that consumed a 4\% cholesterol diet (HCD) or 4\% cholesterol and $50 \%$ fructose (high cholesterol and high fructose [HCHF]) diet were observed in a $28^{\circ} \mathrm{C}$ system incubator. Images of regenerating fins from live zebrafish were taken at 24-hr intervals up to $144 \mathrm{hr}$ under a stereomicroscope (cat. no. SMZ 168, Motic, Hong Kong) and photographed using a Moticam 2300 CCD camera with Image Proplus software version 4.5.1.22 (Media Cybernetics, Bethesda, MD).

\section{Inhibition CE transfer assay}

A rHDL containing ApoA-I and cholesteryl oleate was synthesized in accordance with our previous report ${ }^{19}$ using 
trace amounts of $\left.{ }^{3} \mathrm{H}\right]$ cholesteryl oleate (TRK886, $3.5 \mu \mathrm{Ci} / \mathrm{mg}$ of ApoA-I; GE Healthcare). The rHDL was immobilized using cyanogen bromide (CNBr)-activated Sepharose 4B resin (Amersham Biosciences) for easy separation after the reaction, in accordance with the manufacturer's instructions. The CE transfer reaction was performed in $300-\mu \mathrm{L}$ reaction mixtures containing human $\mathrm{HDL}_{3}(20 \mu \mathrm{L}, 2 \mathrm{mg} / \mathrm{mL})$ as a CETP source, rHDL-agarose $(20 \mu \mathrm{L}, 0.25 \mathrm{mg} / \mathrm{mL})$ as a CE donor, and human LDL $(20 \mu \mathrm{L}, 0.25 \mathrm{mg} / \mathrm{mL})$ as a CE acceptor. Anacetrapib (cat. no. MK-0859, APExBio), PCO, and PCO-rHDL were added to the reaction mixture as an inhibitor. After incubation at $37^{\circ} \mathrm{C}$, the reaction was halted via brief centrifugation $(10,000 \times g)$ for $3 \mathrm{~min}$ at $4^{\circ} \mathrm{C}$. Supernatant containing the $\mathrm{CE}$ acceptor $(150 \mu \mathrm{L})$ was then subjected to scintillation counting, and percentage transfer of $\left[{ }^{3} \mathrm{H}\right] \mathrm{CE}$ from rHDL to LDL was calculated. The extent of CETP inhibition was calculated as follows:

$\%$ inhibnition $=100 \times\left\{1-\left[\frac{\text { sample }(\mathrm{cpm})-\text { blank }(\mathrm{cpm})}{\text { control }(\mathrm{cpm})-\text { blank }(\mathrm{cpm})}\right]\right\}$,

where the sample is rHDL containing PCO treated as an inhibitor source and the control is without inhibitor.

\section{Imaging of ROS}

After rHDL injection, ROS levels in fin tissue were imaged by DHE (cat. no. 37291, BioChemika) staining, as described previously. ${ }^{20}$ The image was obtained by fluorescence observation $(E x=588 \mathrm{~nm}$ and $E m=605 \mathrm{~nm})$ using a Nikon Eclipse TE2000 microscope (Tokyo, Japan).

\section{In vivo test}

Zebrafish maintenance and procedures were approved by the Committee of Animal Care and Use of Yeungnam University (Gyeongsan, Korea). A HCD containing 4\% cholesterol was made by soaking Tetrabit (cat no. D49304, Gmbh) with $47.5 \%$ crude protein, $6.5 \%$ crude fat, $2.0 \%$ crude fiber, $10.5 \%$ crude ash, vitamin A $(29,770 \mathrm{IU} / \mathrm{kg})$, vitamin D3 $(1860 \mathrm{IU} / \mathrm{kg})$, vitamin E $(200 \mathrm{mg} / \mathrm{kg})$, and vitamin C (137 mg/kg; Melle, Germany) with or without PCO in diethyl ether solution of cholesterol (cat. no. C-3045, Sigma). Each group $(n=100)$ consumed its assigned diet $(10 \mathrm{mg} /$ day per fish), as shown in Table 1 . The final amount of PCO in the Tetrabit (wt/wt) was $0.003 \%$ or $0.3 \mu \mathrm{g}$ per zebrafish ( $400 \mathrm{mg}$ body weight), which corresponds to the same dosage $(40 \mathrm{mg})$ of PCO in humans $(60 \mathrm{~kg}$ body weight). Each group $(n=100)$ consumed its designated diet (10 mg of diet/day per fish), as shown in Table 1. Zebrafish were maintained at $28 \pm 1{ }^{\circ} \mathrm{C}$ under a 14 :10-hr light:dark cycle. After feeding for 9 weeks, blood $(2 \mu \mathrm{L})$ was drawn from hearts of adult fish, combined with $5 \mu \mathrm{L}$ of phosphatebuffered saline (PBS)-EDTA (final concentration, $1 \mathrm{mM}$ ) and then collected in EDTA-treated tubes.

\section{Plasma analysis}

TC, HDL-C, and TGs were determined using commercial assay kits (cholesterol, T-CHO, and TGs, Cleantech TS-S; Wako Pure Chemical, Osaka, Japan). Aspartate transaminase (AST) and alanine transaminase (ALT) were measured using a commercially available assay kit (Asan Pharmaceutical, Hwasung, Korea). The CETP activity of zebrafish plasma was compared between the groups as described previously. ${ }^{22}$

\section{Histologic analysis}

After zebrafish were sacrificed, their livers were fixed in $4 \%$ paraformaldehyde for $24 \mathrm{hr}$. Fixed tissues were then embedded in Tissue-Tek OCT compound (Thermo, Walldorf, Germany) and frozen. Next, the frozen tissue blocks were positioned in a model Leica CM1510S cryotome (Nussloch, Germany), and 7- $\mu \mathrm{m}$ serial sections of the ascending aorta were collected on 3-aminopropyltriethoxysilane-coated slides. Seven consecutive sectioned slides from each zebrafish were then stained with Oil Red O and counterstained with Hematoxylin to detect fatty streak lesions in accordance with standard protocols. To compare inflammatory responses in

Table 1. Serum Profiles of Zebrafish After 9 Weeks Consumption of Policosanol Under Presence of Normal Diet or High Cholesterol Diet

\begin{tabular}{lccc}
\hline & $\begin{array}{c}\text { Normal diet } \\
\text { control }(\mathrm{n}=67)\end{array}$ & $\begin{array}{c}\text { High-cholesterol diet } \\
\text { control }(\mathrm{n}=70)\end{array}$ & $\begin{array}{c}\text { HCD }+ \text { policosanol } \\
(\mathrm{n}=80)\end{array}$ \\
\hline Weight $(\mathrm{mg})$ & $396 \pm 45^{\mathrm{a}}$ & $444 \pm 40^{\mathrm{b}}$ & $446 \pm 52^{\mathrm{b}}$ \\
CETP (\%) & $26 \pm 3^{\mathrm{a}}$ & $52 \pm 4^{\mathrm{b}}$ & $28 \pm 2^{\mathrm{a}}$ \\
Total cholesterol (mg/dL) & $98 \pm 4^{\mathrm{a}}$ & $295 \pm 10^{\mathrm{b}}$ & $178 \pm 6^{\mathrm{c}}$ \\
Triglycerides (mg/dL) & $67 \pm 14^{\mathrm{a}}$ & $166 \pm 6^{\mathrm{b}}$ & $110 \pm 3^{\mathrm{c}}$ \\
HDL-C (mg/dL) & $15 \pm 2^{\mathrm{b}}$ & $37 \pm 2^{\mathrm{c}}$ \\
HDL-C/TC (\%) & $29 \pm 2^{\mathrm{a}}$ & $5 \pm 1^{\mathrm{b}}$ & $20 \pm 2^{\mathrm{c}}$ \\
Glucose (mg/dL) & $29 \pm 2^{\mathrm{a}}$ & $94 \pm 4^{\mathrm{b}}$ & $50 \pm 5^{\mathrm{a}}$ \\
AST (Karmen/mL) & $44 \pm 3^{\mathrm{a}}$ & $526 \pm 6^{\mathrm{b}}$ & $225 \pm 11^{\mathrm{c}}$ \\
ALT (Karmen/mL) & $266 \pm 14^{\mathrm{a}}$ & $104 \pm 4^{\mathrm{a}}$ & $84 \pm 5^{\mathrm{ab}}$ \\
\hline
\end{tabular}

Normal diet was Tetrabit ${ }^{\circledR}$ : Tetrabit $(47.5 \%$ crude protein, $6.5 \%$ crude fat, $2.0 \%$ crude fiber, $10.5 \%$ crude ash, containing vitamin A [29,770 IU/kg], vitamin D3 [1860 IU/kg], vitamin E [200 mg/kg], and vitamin C [137 mg/kg]).

High-cholesterol diet was Tetrabit $+4 \%$ cholesterol.

$\mathrm{HCD}+$ policosanol was $0.3 \mu \mathrm{g} \mu \mathrm{g}$ of policosanol in $10 \mathrm{mg}$ of HCD per each zebrafish.

${ }^{a, b}$ The mean values not sharing a common letter in the same row are significantly different in the same groups $(p<0.05)$.

HCD, high- cholesterol diet; CETP, cholesterol ester transfer protein; TC, total cholesterol; HDL-C, high-density lipoprotein cholesterol; AST, aspartate transaminase; ALT, alanine transaminase. 
tissues, levels of ROS were imaged using DHE (cat. no. 37291, Sigma, St. Louis, MO) as described previously following microtome sectioning. ${ }^{23}$ The image was obtained by fluorescence $(E x=588 \mathrm{~nm}$ and $E m=615 \mathrm{~nm})$ using a Nikon Eclipse TE2000 microscope (Tokyo, Japan). Section fluorescence was quantified via computer-assisted morphometry using Image Proplus software (v. 4.5.1.22, Media Cybernetics, Bethesda, MD).

Aliquots of hepatic tissue ( $50 \mathrm{mg}$ of liver in $0.5 \mathrm{~mL}$ of PBS) from each group were homogenized for $3 \mathrm{~min}(150 \mathrm{rpm})$ in an ice bath using a tissue homogenizer (Euro-ST; Eurostar, IKAWERKE, Staufen, Germany). After brief centrifugation $(10,000 \times g)$ and protein determination using Bradford reagent, equally diluted supernatants $(100 \mu \mathrm{g}$ of protein in $0.05 \mathrm{~mL}$ ) were used for determination of oxidative species using the thiobarbituric acid reactive substances (TBARS) method. ${ }^{24}$ In the aliquot of the homogenate, TC, CE, and TGs content was quantified by commercially available assay kits and thin-layer chromatography.

\section{Data analysis}

All data are expressed as the mean \pm standard deviation (SD) from at least three independent experiments with duplicate samples. Data comparisons were assessed by the Student $t$-test using the SPSS program (v. 14.0; SPSS, Inc., Chicago, IL). In the zebrafish study, data in the same group were evaluated via one-way analysis of variance (ANOVA) using SPSS (v. 14.0; Chicago, IL), and the differences between the means were assessed using Duncan's multiplerange test. Statistical significance was defined as a $p<0.05$.

\section{Results}

\section{PCO enhanced growth of brain cells}

PCO and PCO-rHDL treatment facilitated increased growth of human dermal and brain glial cells via inhibition of apoptosis, as shown in Fig. 1. Cells treated with organic solvent and stained with Hematoxylin \& Eosin showed $40 \%$

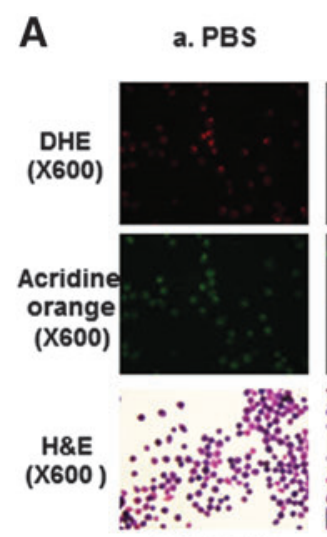

$4.4 \times 10^{5}$ b. Chl-Me
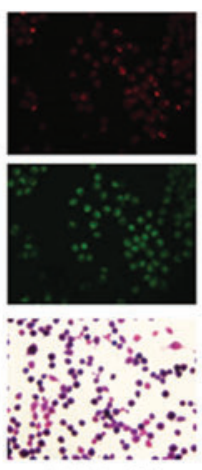

$2.6 \times 10^{5}$ c. $\mathrm{PCO} 9 \mu \mathrm{M}$
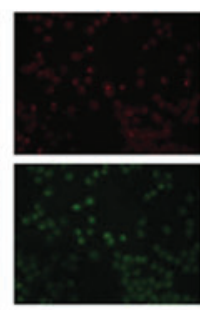

$x^{2}+4=32$

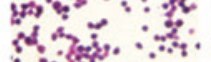

d. $\mathrm{PCO} 46 \mu \mathrm{M}$
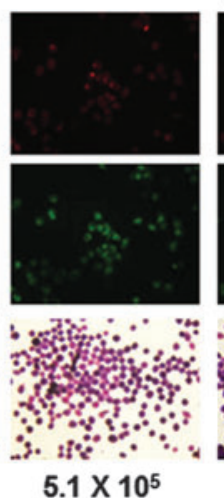

e. rHDL (pA-I:PCO, 1:0)
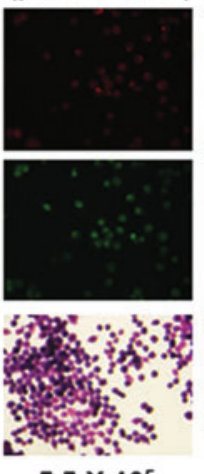
$4.9 \times 10^{5}$

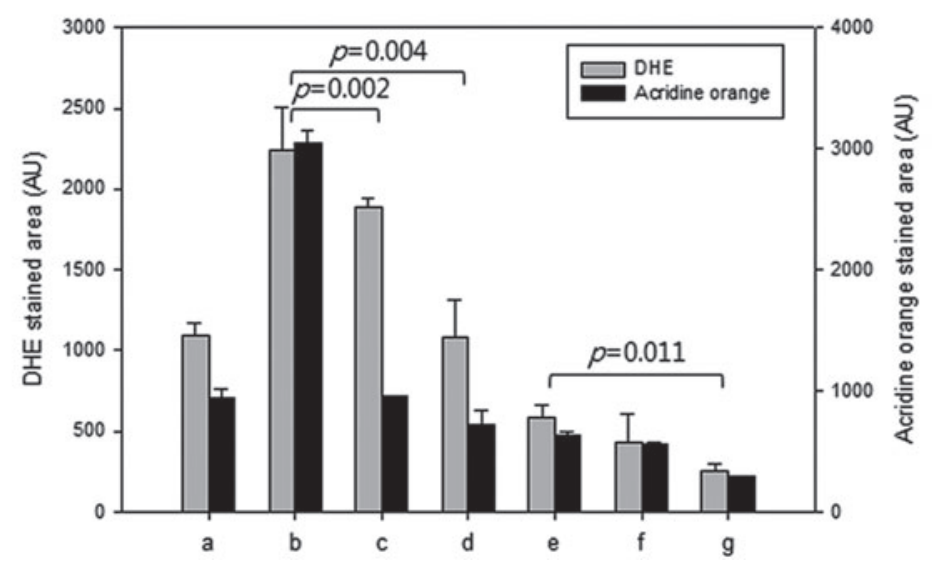

B

FIG. 1. Cytoprotective effect of policosanol (PCO) in BV microglial cells. The extent of apoptosis and reactive oxygen species (ROS) production in BV cells in the presence of PCO either in organic solvent or reconstituted high-density lipoprotein (rHDL). (A) Cellular apoptosis and ROS production were determined by Acridine Orange $(\mathrm{Ex}=502 \mathrm{~nm}$, $E m=525 \mathrm{~nm})$ staining and dihydroethidium $(D H E)$ staining $(E x=588 \mathrm{~nm}, E m=605 \mathrm{~nm})$, respectively. The graph $(\mathbf{B})$ shows quantification of areas stained with Acridine Orange and DHE. (A) Photo a, phosphate-buffered saline (PBS); photo b, organic solvent $\left(\mathrm{CHCl}_{3}: \mathrm{Me}-\mathrm{OH}, 2: 1\right)$; photo c, PCO (final $9 \mu \mathrm{M}$ in $\mathrm{CHCl}_{3}: \mathrm{Me}-\mathrm{OH}$ ); photo d, PCO (final $46 \mu \mathrm{M}$ in $\mathrm{CHCl}_{3}: \mathrm{Me}-\mathrm{OH}$ ); photo e, rHDL (1:0); photo f, PCO-rHDL (1:1), final $9 \mu \mathrm{M}$; photo g, PCO-rHDL (1:5), final $46 \mu \mathrm{M}$. (B) Extent of apoptosis and ROS production in BV cells in the presence of PCO either in organic solvent or rHDL. Acridine Orange. Cellular apoptosis and ROS production were determined by Acridine Orange $(E x=502 \mathrm{~nm}, \mathrm{Em}=525 \mathrm{~nm}) \mathrm{staining}$ and DHE staining $(E x=588 \mathrm{~nm}, E m=605 \mathrm{~nm})$, respectively. Graph shows quantification of areas stained with Acridine Orange and DHE. Color images available online at www.liebertpub.com/rej 


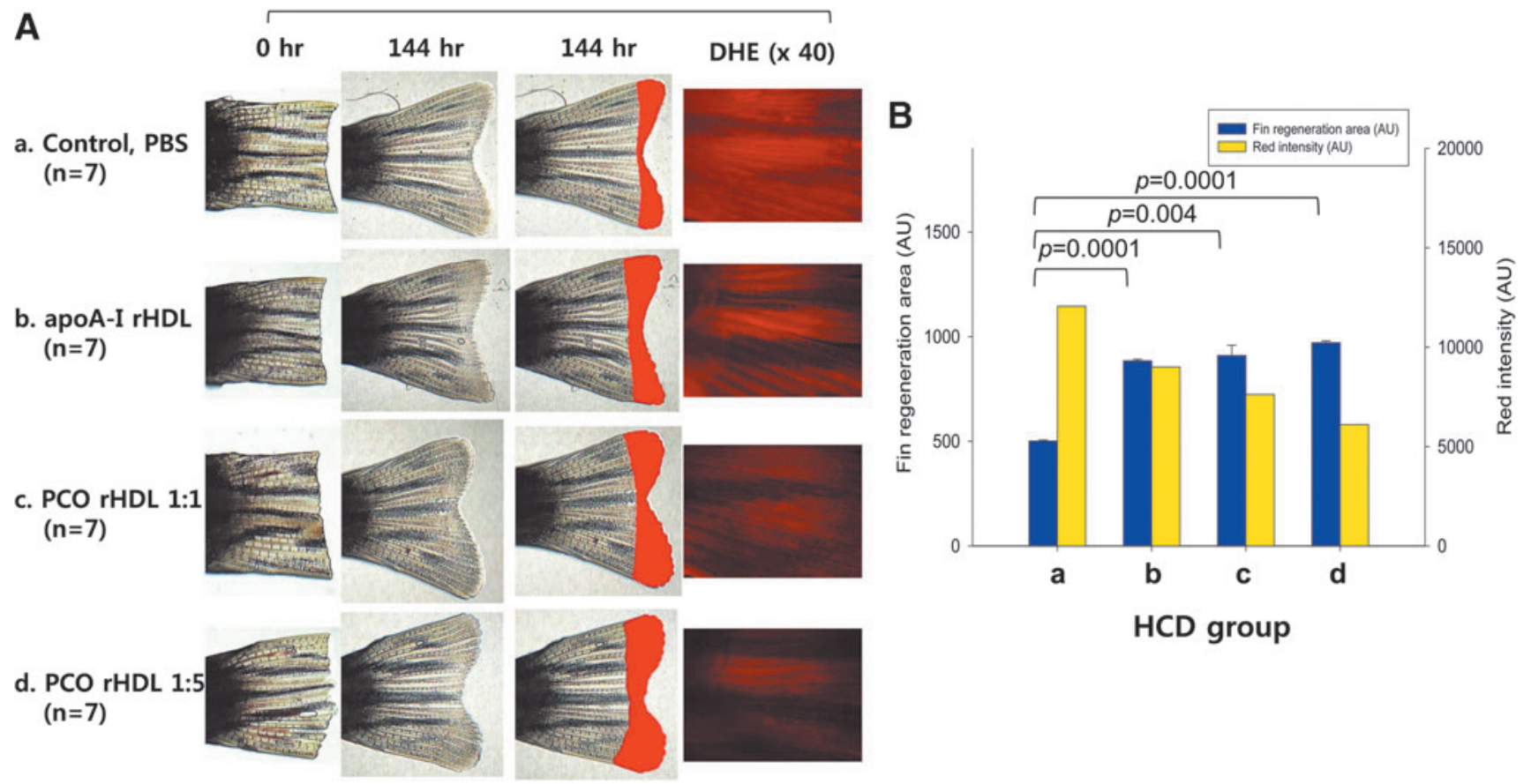

FIG. 2. Tissue regeneration activity of policosanol (PCO) hyperlipidemic zebrafish. Enhancement of zebrafish fin regeneration by injection of reconstituted high-density lipoprotein (rHDL) containing PCO and rHDL ( $2 \mu \mathrm{g}$ of apolipoprotein A-I [Apo-A-I]). (A) Representative image of caudal fin regeneration upon injection of rHDL containing PCO with administration of a high-cholesterol diet (HCD). (B) Fin regeneration area and reactive oxygen species (ROS) production at $144 \mathrm{hr}$ after protein injection. Data shown are the mean \pm standard deviation (SD) of three independent experiments $(n=7)$. Color images available online at www.liebertpub.com/rej

reduced cell numbers compared to PBS-treated cells, indicating cytotoxicity. However, PCO (9 and $46 \mu \mathrm{M})$-treated cells showed 1.8- and 2.0-fold increased numbers, respectively, in organic solvent. rHDL-treated cells showed 1.3-fold higher cell numbers, indicating that native rHDL facilitated cell replication along with suppression of ROS production. PCO-rHDL treatment increased cell numbers.

Acridine Orange staining showed that PCO treatment (final $46 \mu \mathrm{M}$ ) caused $52 \%$ reduction of apoptosis compared to organic solvent, whereas PCO-rHDL caused 58\% reduction of apoptosis compared to rHDL alone. Concomitantly, cell number increased and ROS production decreased upon PCO treatment. PCO-rHDL (1:5)-treated cells showed the highest cell number and lowest ROS production (Fig. 1B), which suggests that the cell proliferation effect of $\mathrm{PCO}$ was synergistically enhanced by rHDL incorporation as PCO content increased.

\section{Tissue regeneration under $H C D$}

As shown in Fig. 2, in zebrafish fed a HCD, injections of rHDL and PCO-rHDL resulted 1.7-fold and 1.9-fold increases, respectively, in the regeneration area compared to the zebrafish injected with PBS. DHE staining revealed that much lower ROS levels in PCO-rHDL-injected zebrafish than rHDL-alone group, suggesting that incorporation of PCO enhanced HDL functionality. ROS production was reduced in the PCO-rHDL group up to 50\% (graph of Fig. 2) compared with PBS-injected group

Under HCHF diet conditions, the rHDL-injected group showed slightly enhanced tissue regeneration activity, indicating that regeneration was more reduced than HCD due to

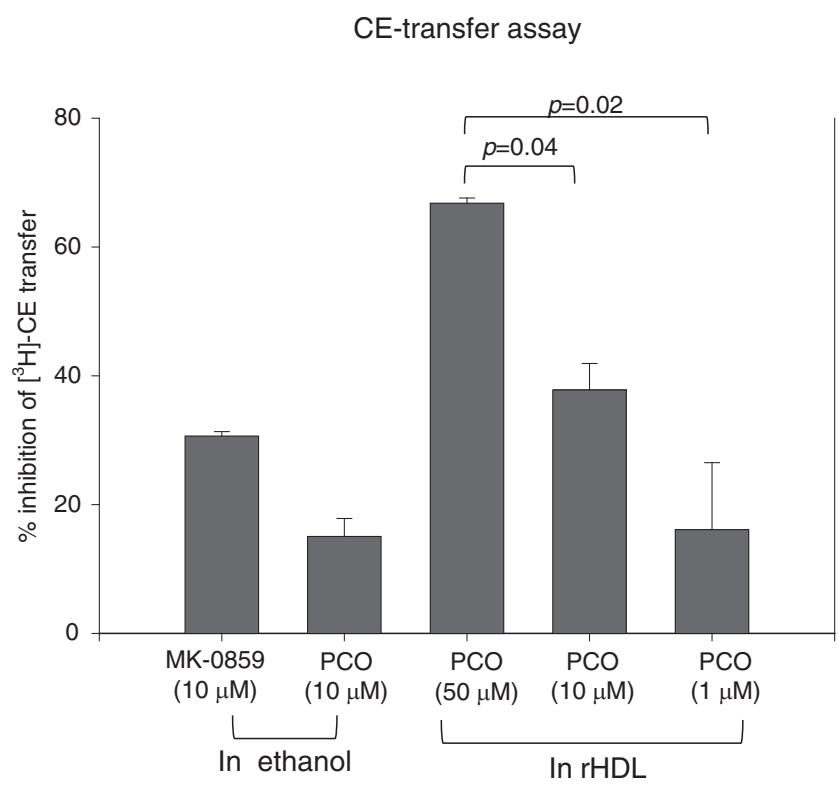

FIG. 3. Cholesteryl ester transfer protein (CETP) inhibitory activity of reconsituted high-density lipoprotein (rHDL) containing policosanol (PCO). Data shown are the mean \pm standard deviation (SD) of three independent experiments performed in duplicate. Cholesteryl ester (CE) transfer from $\left[{ }^{3} \mathrm{H}\right] \mathrm{HDL}$ (50 $\mu \mathrm{g}$ of apolipoprotein A-I [ApoA-I], 30,000 cpm) to human low-density lipoprotein (LDL) (50 $\mu \mathrm{g}$ of protein) by human $\mathrm{HDL}_{3}$ ( $25 \mu \mathrm{g}$ of protein) was inhibited by rHDL containing PCO. 
high fructose consumption and diabetic conditions (Fig. S1) (Supplementary Data are available at www.liebertonline.com/rej/). However, PCO-rHDL injection caused remarkable enhancement of tissue regeneration in a $\mathrm{PCO}$ dose-dependent manner.

\section{In vitro CETP inhibition}

Anacetrapib (MK-0859, final $10 \mu \mathrm{M}$ in EtOH), a well known CETP inhibitor, resulted in $30 \%$ inhibition in vitro, whereas PCO (final $10 \mu \mathrm{M}$ ) in EtOH resulted in $15 \%$ inhibition (Fig. 3). On the other hand, PCO-rHDL resulted in $37 \%$ inhibition (final $10 \mu \mathrm{M}$ ), suggesting that incorporation of PCO into HDL enhanced more CETP inhibitory ability.
Although anacetrapib resulted in higher inhibition than PCO in EtOH, PCO-rHDL in physiologic buffer resulted in higher inhibition than anacetrapib. Furthermore, PCO-rHDL resulted in up to $67 \%$ inhibition (final $50 \mu \mathrm{M}$ ), suggesting a synergistic effect between PCO and rHDL for enhancement of CETP inhibitory activity and functionality.

\section{Consumption of PCO}

Over the course of 9 weeks, each zebrafish consumed $0.3 \mu \mathrm{g}$ of PCO daily under a HCD, which corresponds to $40 \mathrm{mg}$ of PCO per 60-kg human. The ND and HCD groups showed $67 \%$ and $70 \%$ survival rates, respectively. However,
A

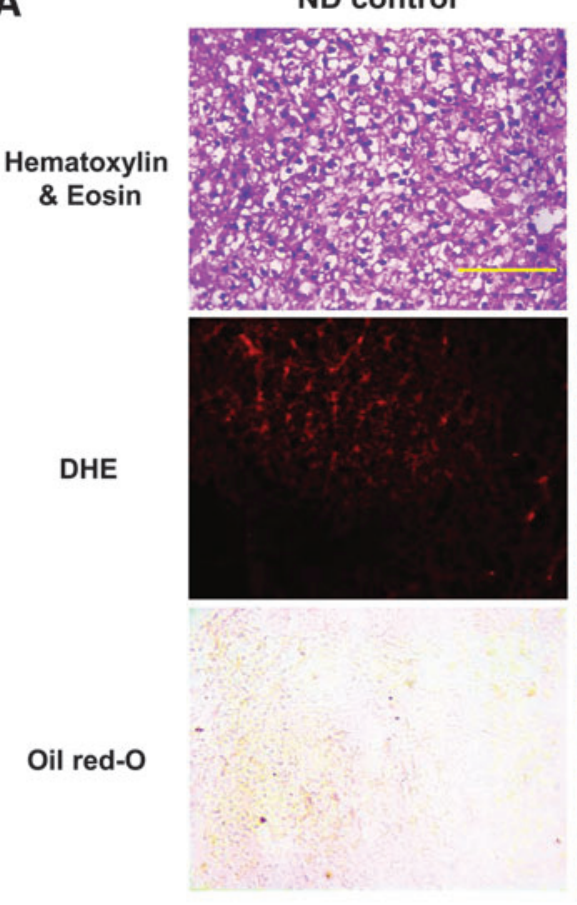

HCD control
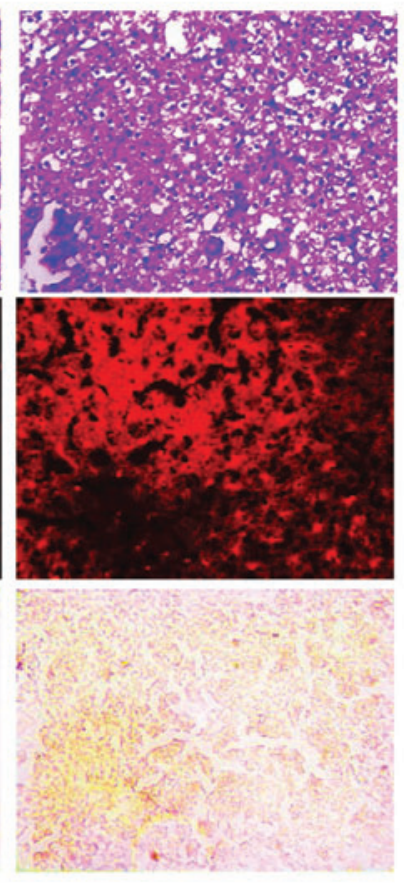
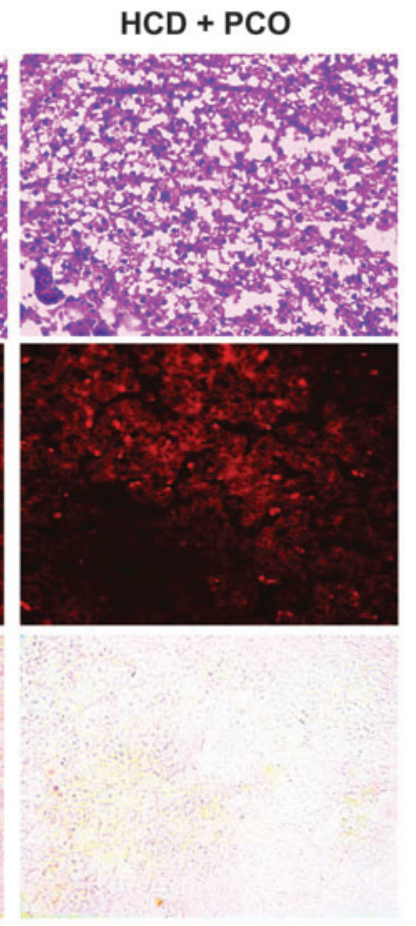
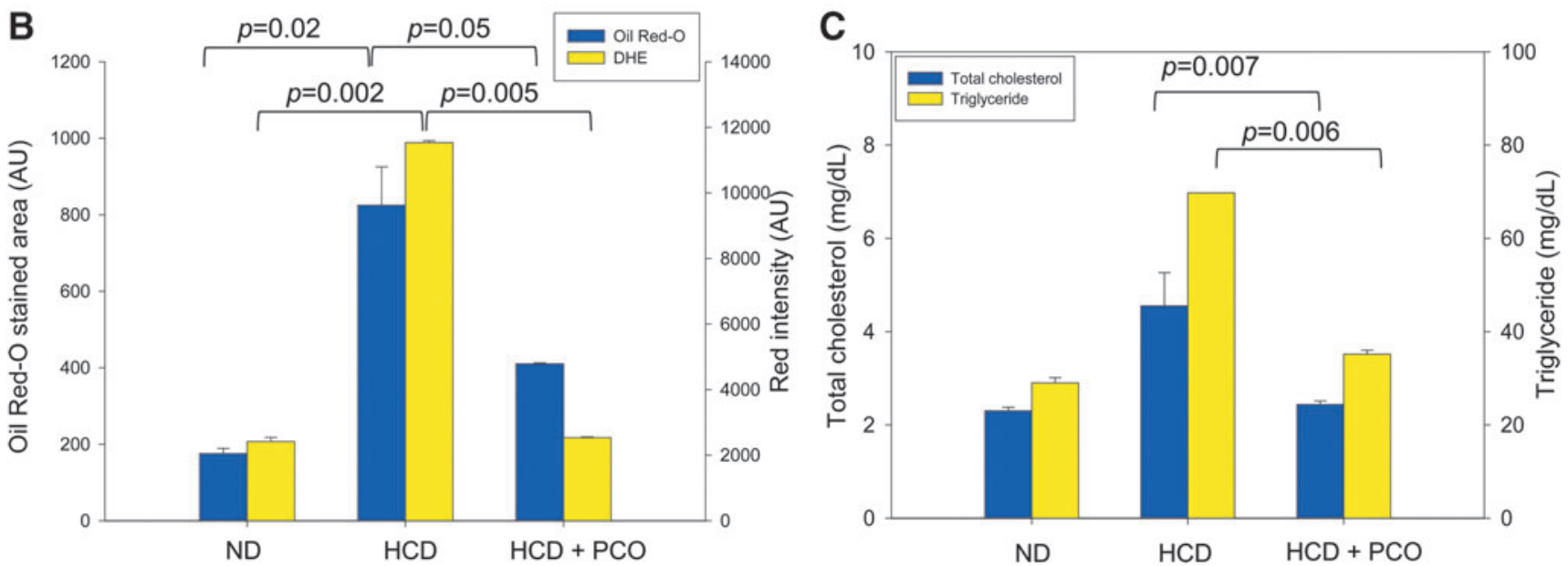

FIG. 4. Histological analysis of hepatic tissue and lipid quantification. (A) Representative photos for comparison of fatty liver changes in zebrafish as visualized by Oil Red $\mathrm{O}$ staining and reactive oxygen species (ROS) production as visualized by dihydroethidium (DHE) staining. Scale bar, $100 \mu \mathrm{m}$. ND, normal diet; HCD, high-cholesterol diet; HCD + PCO (policosanol). Hemaotxylin \& Eosin staining to detect infiltrated inflammatory cells. (B) Quantification of Oil Red O- and DHE-stained area (red fluorescence, Ex $=588 \mathrm{~nm}, \mathrm{Em}=615 \mathrm{~nm}$ ). $(\mathbf{C})$ Quantification of total cholesterol and triglycerides in hepatic tissue as described in text. Color images available online at www.liebertpub.com/rej 
the PCO group $(0.3 \mu \mathrm{M})$ group showed $80 \%$ survivability, indicating that PCO consumption enhanced survival (Fig. S2). The HCD and HCD + PCO groups showed similar extents of increases in body weight.

As shown in Table 1, the HCD group showed 3- and 2.5fold higher serum TC and TGs levels than the ND group, respectively, after 9 weeks of consumption. However, the PCO group $(0.3 \mu \mathrm{g})$ showed $40 \%$ and $33 \%$ lower TC and TGs levels than the HCD control, respectively. The HCD control showed two-fold higher serum CETP activity than the ND control, suggesting that serum CETP activity was elevated by the HCD consumption. However, the PCO group showed remarkably reduced serum CETP activity (48\% reduction, $p=0.012$ ), similar to the ND control group. The serum HDL-C level of the HCD control group was reduced to half that of the ND control group, and the percentage of HDL-C in TC was reduced to only $5 \%$. On the other hand, the PCO group showed remarkable elevation of HDL-C level up to $37 \mathrm{mg} / \mathrm{dL}$, and the percentage of HDL-C increased up to $20 \%$. The serum glucose level of the HCD control was 2.1-fold higher than that for the ND control. However, the PCO group showed $53 \%$ reduction of glucose level, which was similar to the ND control.

Serum glutamic oxaloacetic transaminase (GOT) and glutamic pyruvic transaminase (GPT) levels were elevated under HCD consumption, whereas the PCO group showed a $58 \%$ reduction of enzyme levels. These results indicate that PCO consumption reduced serum TC, TGs, and glucose levels with hepatic inflammatory enzyme levels.

\section{Hepatic tissue histology and lipid content}

After 9 weeks, HCD control showed severe infiltration of inflammatory cells such as neutrophils as well as higher production of ROS by H\&E and DHE staining, respectively. The PCO group showed remarkably reduced infiltration and ROS production. Oil Red O staining revealed that the HCD group contained 4.7-fold more fatty streak lesions than the ND group, as shown in Fig. 4A. DHE staining showed that
ROS production was 4.7-fold higher in the HCD group than the ND group. However, the PCO group showed 50\% and $80 \%$ reduced Oil Red O staining and ROS production, respectively, indicating that $\mathrm{PCO}$ consumption ameliorated fatty liver changes and hepatic inflammation as shown in Fig. 4B.

Lipid determination in the homogenate of hepatic tissue revealed that the HCD group showed the highest cholesterol and TGs content, a two-fold more increase than the ND control group (Fig. 4C). However, $\mathrm{PCO}+\mathrm{HCD}$ group showed around $50 \%$ of reduction in cholesterol and TGs level compared with HCD group.

\section{Ferric ion reduction ability of hepatic tissue}

As shown in Fig. 5A, a ferric ion reduction ability assay using a homogenate of hepatic tissue ( $50 \mu \mathrm{g}$ per group) revealed that the PCO group showed the highest reduction ability (up to $35 \%$ increase from initial level), whereas the ND and HCD groups showed $29 \%$ and $24 \%$ increases, respectively. The MDA level in the homogenate of the HCD group was two-fold higher compared to the ND group, as shown in Fig. 5B, suggesting that high cholesterol consumption may be associated with production of ROS and inflammation. However, the PCO group showed a 50\% lower MDA level than the HCD group, indicating enhancement of anti-oxidant ability and less ROS production upon PCO consumption.

\section{Discussion}

Many animal studies have investigated the lipid-lowering effect of PCO, although the precise mechanism is still unknown. Due to its poor solubility in water, it is very hard to investigate the mechanism of action of PCO. It is plausible that HDL-C is associated with enhancement of endothelial cell function and anti-oxidant capacity in blood vessels. We hypothesized that enhancement of HDL quality could stimulate cell growth and tissue regeneration because enhancement of HDL is associated with anti-thrombotic, anti-
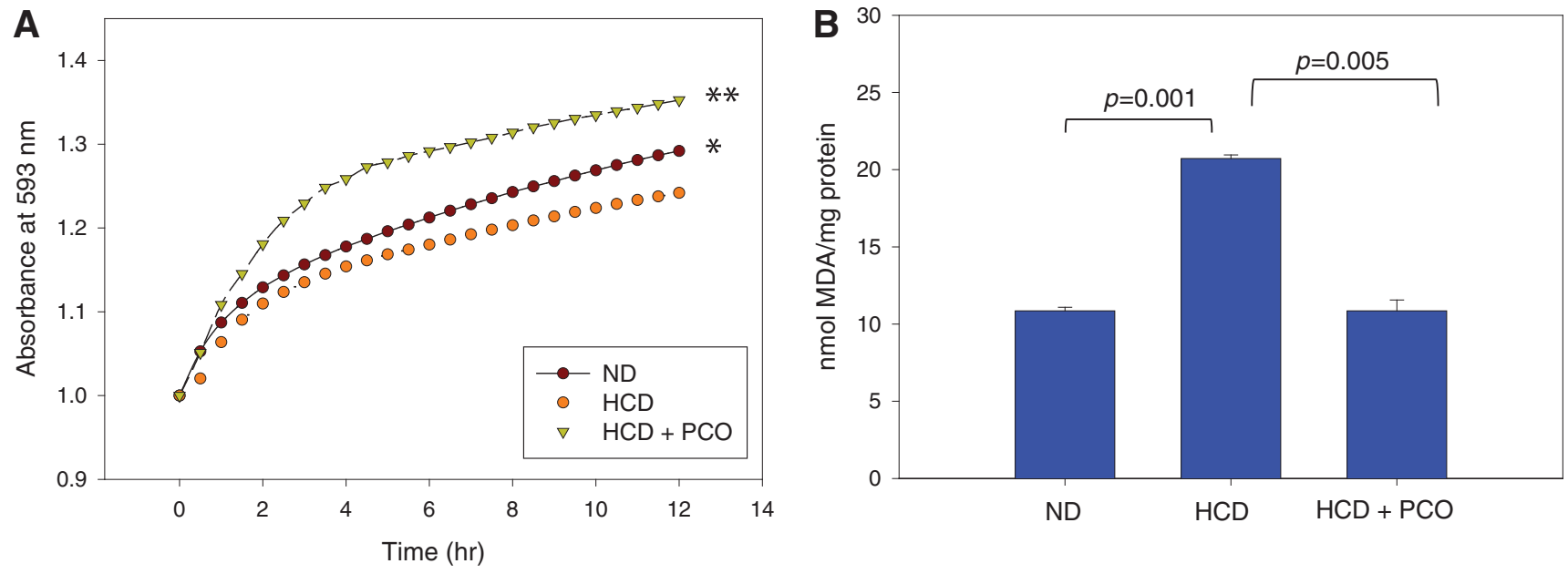

FIG. 5. Anti-oxidant ability of homogenate of hepatic tissue from each group. (A) Ferric ion reduction ability of hepatic tissue $(50 \mu \mathrm{g}$ in phosphate-buffered saline [PBS]). (*) $p<0.05$ versus HCD; (**) $p<0.01$ versus high-cholesterol diet (HCD). (B) Quantification of oxidized species (malondialdehyde) in hepatic tissue (50 $\mu \mathrm{g}$ in PBS). ND, normal diet; HCD, high-cholesterol diet; HCD + PCO (policosanol). Color images available online at www.liebertpub.com/rej 
apoptotic, and vasodilation stimulatory effects. ${ }^{25}$ Indeed, in the current study, we observed that PCO in rHDL stimulated the growth rate of brain glioma cells via anti-apoptosis (Fig. 1) and tissue regeneration activities along with less ROS production under hypercholesterolemic (Fig. 2) and diabetic states (Fig. S1).

Interestingly, as shown in Fig. 3, PCO-rHDL showed higher inhibitory ability against human CETP than MK-0859 at the same dosage (final $10 \mu \mathrm{M}$ ), whereas PCO in EtOH did not. This result suggests that PCO-rHDL interfered with normal interactions between CE-donor (HDL), CETP, and $\mathrm{CE}$ acceptor (LDL). Regarding the detailed mechanism of CE transfer, a recent study reported that CETP binds to HDL via hydrophobic interactions, because HDL surface lipid curvature generates a hydrophobic environment. ${ }^{26}$ Several reports on CETP inhibitors have suggested a putative mechanism for CETP inhibition on the basis of competitive interactions with CETP and HDL. ${ }^{27,28}$

It is possible that aliphatic chains in PCO interfere with binding between CETP and HDL. Otherwise, aliphatic chains bind to a CE-binding site in the carboxyl terminus of CETP to form a ternary complex, as proposed previously. ${ }^{29,30}$ It has been proposed that the carboxyl terminus of CETP (amino acids 453-476) contains an active site and binding pocket for $\mathrm{CE}$ and TG, respectively. Especially, a 12-amino-acid region (amino acids 453-476) forms an amphipathic $\alpha$-helical region and is critical to the transfer process. ${ }^{31}$ A component of PCO in HDL can bind to the amphipathic $\alpha$-helix and block CE/ TGs transfer from HDL to LDL by interfering with CETP and LDL binding.

In our recent report, we showed that CETP inhibitory activity was more enhanced by incorporation of PCO into rHDL, and a low concentration $(10 \mu \mathrm{M})$ was sufficient to exert CETP inhibition. ${ }^{32}$ Taken together with our current results, PCO may interfere with HDL and LDL binding to CETP to form a hydrophobic channel. Enhanced LDL catabolism and reduced TGs metabolism can be accelerated by inhibition of CETP. Because increased serum TGs levels induce production of small dense $\mathrm{LDL}^{33}$ and dysfunctional HDL, ${ }^{34,35}$ it is well established that CETP inhibition is a potent anti-atherogenic strategy. Due to higher CETP activity, low HDL-C levels and prevalence of dysfunctional HDL become risk factors of autoimmune disease with inflammation, vitiligo, ${ }^{36}$ and systemic lupus erythematosus. ${ }^{37}$ Thus, inhibition of CETP by PCO might have antiinflammation and anti-aging effects, resulting in increased cellular replication (Fig. 1) and tissue regeneration (Fig. 2).

On the other hand, loss-of-function mutations in the CETP gene are negatively associated with incidence of coronary artery disease ${ }^{38}$ and have been implicated in longevity. ${ }^{9} \mathrm{~A}$ carboxy-terminal peptide CETP is involved in amyloid fibril formation, especially in the presence of lysophosphatidic acid. ${ }^{39}$ Regarding longevity and CETP, HDL functions to remove lysophospholipids via activation of lecithin:cholesterol acyltransferase (LCAT) and paraoxonase (PON). Thus, suppression of CETP activity and activation of LCAT and PON contribute to enhancement of HDL functionality to exert anti-aging activities. In the animal study, the PCO group showed higher survivability (Fig. S2), lower fatty liver changes (Fig. 4A), less ROS production (Fig. 4B), and lower lipid accumulation in hepatic tissue (Fig. 4C). Although PCO consumption has been shown to lower LDL-C and raise se- rum HDL-C levels, its physiological functions have not been reported. $^{40}$ This is the first report demonstrating the antiaging effect of $\mathrm{PCO}$ via enhancement of HDL functionality in a live vertebrate model. HDL-C is inversely related to incidence of coronary heart disease. In addition to antiatherosclerosis activity, the anti-aging activity of HDL is critical to the maintenance of health via potent anti-oxidant and anti-inflammatory activities.

Although comparison of the PCO feeding dosage between zebrafish and humans is difficult, the daily amount of PCO $(0.3 \mu \mathrm{g})$ per zebrafish $(400 \mathrm{mg})$ corresponded to a dosage of $40 \mathrm{mg} /$ day per $60 \mathrm{~kg}$ in humans. Survivability was slightly but significantly enhanced between the ND group and HCD group after 9 weeks of PCO consumption (Fig. S2) with remarkable lipid reduction and HDL-C elevation (Table 1). Unexpectedly, reduction of glucose and hepatic inflammation was observed in the PCO group. The glucose-lowering effect of the PCO group (47\% lower than that of the HCD control) might be associated with adenosine monophosphate (AMP)-activated protein kinase (AMPK) activation, resulting in suppression of HMG-CoA reductase activity, as suggested previously. ${ }^{41}$

It is likely that PCO interacts with other lipoproteins, especially HDL, after uptake with chylomicron or very-lowdensity lipoprotein (VLDL) and release into the serum. However, the beneficial activity of HDL can be degenerated by aging stress, such as glycation and oxidation. Indeed, HDL functionality and structure can be modified by foreign molecules such as trans fatty acids ${ }^{22}$ and artificial sweeteners. ${ }^{13}$

In the current report, the physiological effect of PCO was investigated in brain cells (neuroglyoma) and hypercholesterolemic zebrafish. Conclusively, PCO exerted antiapoptotic activity, resulting in increased cell replication and tissue regeneration. Nine weeks of consumption of PCO resulted in reduction of serum TC and TGs levels, increased HDL-C levels via CETP inhibition, and amelioration of fatty liver changes.

\section{Acknowledgments}

This work was supported by a grant from the Mid-carrier Researcher Program (grant no 2014-11049455) and Medical Research Center Program (grant no. 2015R1A5A2009124) through the National Research Foundation (NRF), funded by the Ministry of Science, ICT and Future Planning of Korea.

\section{Author Disclosure Statement}

No competing financial interests exist.

\section{References}

1. Wang YW, Jones PJ, Pischel I, Fairow C. Effects of policosanols and phytosterols on lipid levels and cholesterol biosynthesis in hamsters. Lipids 2003;38:165-170.

2. Menéndez R, Arruzazabala L, Más R, Del Río A, Amor AM, González RM, Carbajal D, Fraga V, Molina V, Illnait J. Cholesterol-lowering effect of policosanol on rabbits with hypercholesterolaemia induced by a wheat starchcasein diet. Br J Nutr 1997;77:923-932.

3. Arruzazabala ML, Carbajal D, Mas R, Molina V, Valdes S, Laguna A. Cholesterol-lowering effects of policosanol in rabbits. Biol Res 1994;27:205-208. 
4. Rodríguez-Echenique $\mathrm{C}$, Mesa R, Más R, Noa M, Menéndez R, González RM, Amor AM, Fraga V, Sotolongo V, Laguna A. Effects of policosanol chronically administered in male monkeys (Macaca arctoides). Food Chem Toxicol 1994;32:565-575.

5. Noa M, de la Rosa MC, Más R. Effect of policosanol on foam-cell formation in carrageenan-induced granulomas in rats. J Pharm Pharmacol 1996;48:306-309.

6. Menéndez R, Amor AM, Rodeiro I, González RM, González PC, Alfonso JL, Más R. Policosanol modulates HMGCoA reductase activity in cultured fibroblasts. Arch Med Res 2001;32:8-12.

7. Eghdamian B, Ghose K. Mode of action and adverse effects of lipid lowering drugs. Drugs Today (Barc) 1998;34:943956.

8. Tsutsumi K, Hagi A, Inoue Y. The relationship between plasma high density lipoprotein cholesterol levels and cholesteryl ester transfer protein activity in six species of healthy experimental animals. Biol Pharm Bull 2001;24: 579-581.

9. Barzilai N, Atzmon G, Schechter C, Schaefer EJ, Cupples AL, Lipton R, Cheng S, Shuldiner AR. Unique lipoprotein phenotype and genotype associated with exceptional longevity. JAMA 2003;290:2030-2040.

10. Cho KH. Biomedicinal implications of high-density lipoprotein: Its composition, structure, functions, and clinical applications. BMB Rep 2009;42:393-400.

11. Reitz C, Tang MX, Schupf N, Manly JJ, Mayeux R, Luchsinger JA. Association of higher levels of high-density lipoprotein cholesterol in elderly individuals and lower risk of late-onset Alzheimer disease. Arch Neurol 2010;67: 1491-1497.

12. Vitali C, Wellington CL, Calabresi L. HDL and cholesterol handling in the brain. Cardiovasc Res 2014;103:405-413.

13. Kim JY, Seo J, Cho KH. Aspartame-fed zebrafish exhibit acute deaths with swimming defects and saccharin-fed zebrafish have elevation of cholesteryl ester transfer protein activity in hypercholesterolemia. Food Chem Toxicol 2011; 49:2899-2905.

14. Stoletov K, Fang L, Choi SH, Hartvigsen K, Hansen LF, Hall C, Pattison J, Juliano J, Miller ER, Almazan F, Crosier P, Witztum JL, Klemke RL, Miller YI. Vascular lipid accumulation, lipoprotein oxidation, and macrophage lipid uptake in hypercholesterolemic zebrafish. Circ Res 2009; 104:952-960.

15. Havel RJ, Eder HA, Bragdon JH. The distribution and chemical composition of ultracentrifugally separated lipoproteins in human serum. J Clin Invest 1955;34:1345-1353.

16. Pongor S, Ulrich PC, Bencsath FA, Cerami A. Aging of proteins: Isolation and identification of a fluorescent chromophore from the reaction of polypeptides with glucose. Proc Natl Acad Sci USA 1984;81:2684-2688.

17. Cho KH. Synthesis of reconstituted high density lipoprotein (rHDL) containing apoA-I and apoC-III: The functional role of apoC-III in rHDL. Mol Cells 2009;27:291-297.

18. Yoon JH, Cho KH. A point mutant of apolipoprotein A-I (V156K) showed enhancement of cellular insulin secretion and potent activity of facultative regeneration in zebrafish. Rejuvenation Res 2012;15:313-321.

19. Kim SM, Kim JM, Shin DG, Kim JR, Cho KH. Relation of atrial fibrillation (AF) and change of lipoproteins: Male patients with AF exhibited severe pro-inflammatory and pro-atherogenic properties in lipoproteins. Clin Biochem 2014;47:869-875.
20. Park KH, Cho KH. A zebrafish model for the rapid evaluation of pro-oxidative and inflammatory death by lipopolysaccharide, oxidized low-density lipoproteins, and glycated high-density lipoproteins. Fish Shellfish Immunol 2011;31:904-910.

21. Kim SH, Lee EY, Cho KH. Incorporation of human growth hormone-2 into proteoliposome enhances tissue regeneration with anti-oxidant and anti-senescence activities. Rejuvenation Res 2015;18:20-29.

22. Park KH, Kim JM, Cho KH. Elaidic acid (EA) generates dysfunctional high-density lipoproteins and consumption of EA exacerbates hyperlipidemia and fatty liver change in zebrafish. Mol Nutr Food Res 2014;58:1537-1545

23. Owusu-Ansah E, Yavari A, Mandal S, Banerjee U. Distinct mitochondrial retrograde signals control the G1-S cell cycle checkpoint. Nat Genet 2008;4:356e61.

24. Blois MS. Antioxidant determination by the use of a stable free radical. Nature 958;181:1199-2000.

25. Mineo C, Deguchi H, Griffin JH, Shaul PW. Endothelial and antithrombotic actions of HDL. Circ Res 2006;98: 1352-1364.

26. Zhang M, Charles R, Tong H, Zhang L, Patel M, Wang F, Rames MJ, Ren A, Rye KA, Qiu X, Johns DG, Charles MA, Ren G. HDL surface lipids mediate CETP binding as revealed by electron microscopy and molecular dynamics simulation. Sci Rep 2015;5:8741.

27. Ranalletta M, Bierilo KK, Chen Y, Milot D, Chen Q, Tung E, Houde C, Elowe NH, Garcia-Calvo M, Porter G, Eveland S, Frantz-Wattley B, Kavana M, Addona G, Sinclair P, Sparrow C, O'Neill EA, Koblan KS, Sitlani A, Hubbard B, Fisher TS. Biochemical characterization of cholesteryl ester transfer protein inhibitors. J Lipid Res 2010;51:2739-2752.

28. Cilpa-Karhu G, Jauhiainen M, Riekkola ML. Atomistic MD simulation reveals the mechanism by which CETP penetrates into HDL enabling lipid transfer from HDL to CETP. J Lipid Res 2015;56:98-108.

29. Ihm J, Quinn DM, Busch SJ, Chataing B, Harmony JA. Kinetics of plasma protein-catalyzed exchange of phosphatidylcholine and cholesteryl ester between plasma lipoproteins. J Lipid Res 1982;23:1328-1341.

30. Potter LK, Sprecher DL, Walker MC, Tobin FL. Mechanism of inhibition defines CETP activity: A mathematical model for CETP in vitro. J Lipid Res 2009;50:2222-2234.

31. Wang S, Kussie P, Deng L, Tall A. Defective binding of neutral lipids by a carboxyl-terminal deletion mutant of cholesteryl ester transfer protein. Evidence for a carboxylterminal cholesteryl ester binding site essential for neutral lipid transfer activity. J Biol Chem 1995;270:612-618.

32. IhM S, Yoo JA, Cho KH. Enhancement of HDL functions by encapsulation of policosanol exerts anti-senescence and tissue regeneration effects via improvement of anti-glycation, anti-apoptosis, and cholesteryl ester transfer inhibition. Rejuvenation Res 2015 (accepted)

33. Griffin A. Women's health and the articulation of policy preferences. Setting the terms of discussion. Ann NY Acad Sci 1994; 736:205-216.

34. Park KH, Jang W, Kim KY, Kim JR, Cho KH. Fructated apolipoprotein A-I showed severe structural modification and loss of beneficial functions in lipid-free and lipid-bound state with acceleration of atherosclerosis and senescence. Biochem Biophys Res Commun 2010; 392:295-300.

35. Park KH, Cho KH. High-density lipoprotein (HDL) from elderly and reconstituted HDL containing glycated apolipoproteins A-I share proatherosclerotic and prosenescent 
properties with increased cholesterol influx. J Gerontol A Biol Sci Med Sci 2011;66:511-520.

36. Karadag AS, Tutal E, Ertugrul DT. Insulin resistance is increased in patients with vitiligo. Acta Derm Venereol 2011;91:541-544.

37. McMahon M, Grossman J, FitzGerald J, Dahlin-Lee E, Wallace DJ, Thong BY, Badsha H, Kalunian K, Charles C, Navab M, Fogelman AM, Hahn BH. Proinflammatory highdensity lipoprotein as a biomarker for atherosclerosis in patients with systemic lupus erythematosus and rheumatoid arthritis. Arthritis Rheum 2006;54:2541-2549.

38. Inazu A, Brown ML, Hesler CB, Agellon LB, Koizumi J, Takata K, Maruhama Y, Mabuchi H, Tall AR. Increased high-density lipoprotein levels caused by a common cholesteryl-ester transfer protein gene mutation. N Engl J Med 1990;323:1234-1238.

39. García-González V, Mas-Oliva J. Amyloid fibril formation of peptides derived from the C-terminus of CETP modulated by lipids. Biochem Biophys Res Commun 2013;434:54-59.
40. Gouni-Berthold I, Berthold HK. Policosanol: Clinical pharmacology and therapeutic significance of a new lipidlowering agent. Am Heart J 2002;143:356-365.

41. Singh DK, Li L, Porter TD. Policosanol inhibits cholesterol synthesis in hepatoma cells by activation of AMP-kinase. J Pharmacol Exp Ther 2006;318:1020-1026.

Address correspondence to: Kyung-Hyun Cho School of Biotechnology Yeungnam University Gyeongsan 712-749

South Korea

E-mail: chok@yu.ac.kr

Received: July 13, 2015 Accepted: August 11, 2015 